\title{
O novo homem existe? efeitos de sentido sobre masculinidade
}

\section{Does the new man exist? effects of meaning on masculinity}

\section{¿Existe el nuevo hombre? los efectos de los sentidos en la masculinidad}

\author{
Eliana Cristina Pereira Santos ${ }^{1}$ (iD https://orcid.org/0000-0002-2952-3513
}

\begin{abstract}
RESUMO: Os estudos de gênero, fruto dos movimentos feministas, permitiram estudar além dos feminismos, os masculinos, o gênero masculino. As masculinidades, no plural, enquanto temática de estudo, têm se ampliado em vários campos acadêmicos: sociológico, psicológico, pósestruturalistas e materialistas. Isso ocorre, porque o ser masculino vai além do biológico, é uma construção social, portanto, ideológica, discursivizada. Partindo do argumento de que não existe uma única masculinidade e tendo como aporte teórico a Análise de Discurso pecheutiana, pretendese, neste trabalho, analisar a capa da revista Galileu, de novembro de 2018, que trata sobre a temática "O novo homem existe?". A capa, enquanto materialidade imagética e simbólica, é suporte de discursos que ressignificam efeitos de sentido sobre determinados sujeitos e suas relações sociais. Ou seja, discursiviza sobre as masculinidades. Para analisar o capa dessa revista, mobilizaremos os seguintes conceitos da teoriateóricos: memória discursiva, interdiscurso e as formações discursivas, para trazer para o fio do discurso os efeitos de sentido que incidem sobre a masculinidade, discursivizados na materialidade midiática.
\end{abstract}

PALAVRAS-CHAVE: Discurso. Masculinidades. Revista.

ABSTRACT: Gender studies, fruit of the feminist movements, have made it possible to study besides feminisms, masculinities, the masculine gender. The masculinities, in the plural form, as a theme of study, have been expanded in various academic fields: sociological, psychological, poststructuralist, and materialist. This occurs because being masculine goes beyond the biological; it is a social construction, therefore, ideological, discursivized. Starting from the argument that there is not a single masculinity and having as theoretical contribution the Pecheutian Discourse Analysis, it is intended, in this work, to analyze the cover of Galileu magazine, November 2018, which deals

\footnotetext{
${ }^{1}$ Doutoranda em Letras (UNIOESTE). Professora e Coordenadora do Curso de Pedagogia (FAFIG). E-mail: eliana.foz@gmail.com
} 
with the theme "Does the new man exist?". The cover, as imagetic and symbolic materiality, is a support of discourses that resignify effects of meaning ofcertain subjects and their social relations. That is, it discursivizes about masculinities. To analyze the cover of this magazine, we mobilize the following concepts of theory: discursive memory, interdiscourse and Discursive Formations, to bring to the thread of discourse the effects of meaning about masculinity discursivized in this media materiality.

KEYWORDS: Discourses. Masculinities. Magazine.

RESUMEN: Los estudios de género, fruto de los movimientos feministas, han permitido estudiar más allá de los feminismos, las masculinidades, el género masculino. Las masculinidades, en plural, como tema de estudio, se han expandido en diversos ámbitos académicos: sociológico, psicológico, postestructuralista y materialista. Esto ocurre porque el macho va más allá de lo biológico es una construcción social, por lo tanto, ideológica, discursiva. Partiendo del argumento de que no existe una única masculinidad y teniendo como aportación teórica el Análisis del Discurso Pecheutiano se pretende, en este trabajo, analizar la portada de la revista Galileu, de noviembre de 2018, que trata el tema "¿Existe el nuevo hombre? La portada, como imaginario y materialidad simbólica, es soporte de discursos que resignifican efectos de sentido sobre determinados sujetos y sus relaciones sociales. Es decir, discurre sobre las masculinidades. Para analizar la portada de esta revista, movilizamos los siguientes conceptos de la teoría: memoria discursiva, interdiscurso y formaciones discursivas, para traer al hilo del discurso los efectos de significado sobre la masculinidad discursiva en esta materialidad mediática.

PALABRAS CLAVE: El discurso. Las masculinidades. La revista.

\section{Fios iniciais}

Este trabalho analisa os efeitos de sentido provocados sobre o conceito"ser homem" apresentado na capa da edição de novembro de 2018 da revista Galileu, que coloca como chamada para a matéria principal a indagação: "O novo homem existe?". Criada com o nome Globo Ciência, a revista é divulgada mensalmente, desde 1991, pela Editora Globo, e veicula matérias que abordam assuntos relacionados à ciência, à história, à tecnologia, à religião e à saúde. A publicação é direcionada ao público em geral, uma vez que suas temáticas, ainda que consideradas científicas, apresentam uma linguagem mais acessível que um artigo de pesquisa em revistas especializadas. Galileu traz temáticas da atualidade com os discursos fundamentados em pesquisas acadêmicas, na busca por atender a um público diversificado, sem academicismos.

Para tal análise, utilizaremos como base metodológica e teórica a Teoria do Discurso de origem francesa, uma vez que através desta é possível amparar as análises, e, possibilitar a compreensão da materialidade da linguagem. A linguagem, enquanto mediação, é fundamental para a relação entre os seres humanos, com suas realidades e com a sociedade em que estão inseridos. A linguagem bem distante das viisões 
estruturalistas, mas, por uma ótica em que seu funcionamento e constituição são base material na constituição dos sujeitos e dos sentidos, ou seja, está presente na forma como as pessoas se relacionam. Uma teoria que à sua maneira, num processo de dimensões institucionais e epistemológicas, rompe com o estruturalismo linguístico engessado e abre espaço para o imbricamento da Linguística com a História e a Psicanálise. A teria trabalha com o conceito de noções advindas do materialismo histórico - condições materiais históricas que determinam o nível de ideologia, da psicanálise - com a descoberta do sujeito cindido entre consciente e inconsciente, do marxismo - as condições econômicas, e, a própria linguística que que atravessam e constituem os sujeito e linguagem.

Posto que o ser humano é sujeito da e na linguagem que o constitui, os seguintes conceitos da Análise de Discurso serão utilizados, visando examinar quais processos discursivos são conjugados sob a forma de capa: interdiscurso, memória discursiva e formação discursiva. A formação discursiva é aquilo "que pode e deve ser dito" (PÊCHEUX, 2009, p. 147). Por sua vez, a memória discursiva é entendida como memória social, dentro da formação discursiva em relação de proximidade ao interdiscurso, nas palavras de Pêcheux (2009, p. 149) esse "todo complexo com dominante das formações discursivas"

Dois conceitos importantes serão requisitados durante a análise: o de Formação Discursiva, como um lugar que permite ao sujeito falar, se comportar, enfim, fornece sentidos diferentes dependendo de qual FD ele esteja inscrito, interpelado pela ideologia. Onde é a FD que fornece o sentido, o significando dentro de possibilidades regradas pela própria FD. Parafraseando Santos (2013, p. 39 -79), só há significados, sentidos, quando a FD permite juntamente à memória discursiva, que reconstrói os discursos e reestabelece sentidos, um discurso situado historicamente,

A revista, enquanto materialidade discursiva, constitui um corpus discursivo "como dispositivo de agrupamento e de organização de sequências discursivas regulado pela noção de 'condições de produção do discurso" (CONEIN et al., 2016, p. 33). Ou seja, a capa agrupa um número de elementos dispostos, organizados, regulados pela própria revista. A diagramação, seleção e disposição de cores, tamanho e disposição dos enunciados, são organizados de tal forma, no gênero discursivo capa de revista, que é convidado a ver e oferecido a ler por quem tiver interesse pelo assunto, ou, assinates da revista.

A capa constitui essa organização regulada, uma vez que foi criada sob determinadas condições de produção, e, portanto, provoca efeitos de sentido. Enquanto materialidade 
discursiva, a revista exerce no sujeito leitor processos de significação diversas e suas características são de fundamental importância para que se possa compreender o porquê de determinados efeitos de sentidos serem produzidos a partir dela. A proposta da revista é possibilitar aos seus leitores acesso a assuntos científicos e tecnológicos, sempre buscando vozes autorizadas para dar credibilidade às matérias.

No que tange à edição que é objeto de análise, a temática central é a masculinidade. Para chamar a atenção do leitor, a revista traz na capa a fotografia do cantor, rapper e poeta paulista Rincon Sapiência, também conhecido como Manicongo, vestido com uma saia rodada branca com pequenas estampas pretas. $O$ cantor negro aborda em suas canções a valorização da afrodescendência no Brasil. A fotografia de um homem vestido de saia, em uma cultura em que os homens não usam esta vestimenta, já desperta a atenção do leitor para a reportagem que o uso de um vestuário tipicamente feminino na pele de um ser, sujeito masculino, é uma maneira de performar o masculino. 0 efeito da capa "é antes de tudo um efeito visual que determina essa conversão do olhar pela qual o invisível [...] se deixa enfim ser visto" (PÊCHEUX, 1990, p. 17). Em outras palavras, a capa da revista possibilita circular esse acontecimento histórico da edição, como testemunha ocular, falando em nome de, com a voz de autoridade da imprensa, tornando possível ver um homem vestido de saia.

Os invisíveis seriam as pessoas que se sentem representadas pela capa, afinal, na cultura ocidentalizada brasileira, há um estranhamento quando um homem não é apresentado vestindo calças, principalmente em uma capa de revista, mas a saia causa no leitor certa curiosidade e ao mesmo tempo espanto, além da invisibilidade de pessoas negras em capas de revista. A revista expõe seu olhar e afronta o poder patriarcal e heteronormativo não como adversária, mas uma negociadora potencial. Não chega a ser um acontecimento discursivo, mas, provoca um olhar de estranhamento frente à cultura do país e ao nível estrutural, uma vez que as representações binárias de gênero se impõem como normas estruturantes da dinâmica sociocultural na maioria dos países ocidentais. Por exemplo: a maioria dos homens não costumam usar saia nas sociedades ocidentais. Seria diferente em sociedades em que os sujeitos masculinos usam culturalmente saias e vestidos. Segundo Bourdieu (2010, p. 39), a saia é uma vestimenta que desencoraja ou impossibilita alguns tipos de atividades, são limitadoras de movimentos, e, para o feminino provoca é um tipo de roupa que provoca "um confinamento simbólico". 
Apresentados os fios iniciais, é mister dizer que o presente trabalho está dividido nas seguintes partes:alguns conceitos teóricos sobre gênero, masculinidade e estereótipos; um exercício de análise, considerações sobre os malefícios de uma masculinidade hegemônica e, por fim, à guisa da (in)conclusão, reflexões sobre a possibilidade de existir ou não um novo homem.

\section{Sobre alguns conceitos teóricos}

Com o advento dos movimentos feministas, o recrudescimento dos estudos de gênero e consequentemente com as reflexões sobre as identidades sexuais, particularmente na década de 60, - em que os estudos sobre as mulheres abririam uma gama de outras discussões necessárias essencialmente epistemológicas -, a temática da masculinidade também passou a ser objeto de estudo, uma vez que perpassa as discussões sobre relações de gênero.

Para Scott (1995), as pesquisadoras feministas assinalaram "que o estudo das mulheres não acrescentaria somente novos temas, mas que iria igualmente impor um reexame crítico das premissas e dos critérios do trabalho científico existente" (SCOTT, 1995, p. 73). Há que se reconhecer que foi através dos discursos feministas que as relações de gênero ganharam relevância no meio acadêmico, ou seja, a díade relacional masculinofeminino. $O$ ápice encontra-se na mudança de perspectiva: de estudos de mulheres para estudos de gênero, "o gênero se torna, aliás, uma maneira de indicar as 'construções sociais': a criação inteiramente social das ideias sobre os papéis próprios aos homens e às mulheres" (SCOTT, 1995, p. 3).

O estudo sobre gênero permitiu estudar os femininos e os masculinos, uma vez que se refere às identidades sociais subjetivas do binário: mulher e homem. A construção social - e, portanto, cultural - impõe ao corpo sexuado maneiras de ser, de vestir-se, de relacionar-se, de poderio, de identidades, de subjetividades, de existência dentro de determinados grupos sociais. Os gêneros binários, masculino e feminino são, portanto, uma construção social.

Paralelo aos movimentos feministas podemos visibilizar o movimento queer ${ }^{2}$, que

\footnotetext{
2 Queer: com origem na língua inglesa, era um termo pejorativo para identificar pessoas que não eram aceitas socialmente ou que viviam à margem da lei (como prostitutas, devassos ou desempregado). Mais tarde, a palavra começou a ser
} 
ultrapassa as questões políticas e de teorização da homosexualidade. A teoria queer soma aos movimentos feministas para problematizar as noções estruturalistas sobre sujeito, identidades, a desconstrução/fragmentação do binarismo, entre outros. O sujeito não é mais apenas racional, é também, do inconsciente, do desejo, da ideologia e dos discursos, conforme conceitos apresentados por teóricos como Freud, Lacan, Althusser, Foucalt e Pêcheux.

É importante ressaltar que para Butler (1997), o sujeito só existe na medida em que se sujeita às regulações, às normas, sendo o próprio gênero uma norma, o que denomina de sujeito gendrado, ou seja, um sujeito que é forjado sob sobredeterminação complexas de identificações discursivas e simbólicas de sexualidade e de gênero, configurando sua posição-sujeito dentro de condições de produção e memória discursiva que o interpelam a determinadas normatização do corpo.Resultado de inúmeras repetições que o constituem e impõe efeitos sobre o gênero. Ou seja, o gênero é uma norma que apenas emerge nas relações de gênero. Somos sujeitados e subjetivados pelo gênero, "o 'eu' nem precede, nem segue o processo dessa 'criação de um gênero" (BUTLER, 1993, p. 7).

Em relação aos estereótipos, Amossy (1991, p. 21) afirma que estes são uma construção de leitura, como "representação coletiva cristalizada". São como imagens préconcebidas, fatiadas, abreviadas sob a influência do social. O social permite circular essas representações facetadas deformadas, de maneira que cristaliza no imaginário social a definição de muitas coisas. Os estereótipos constituem lugares de discursos, muitas vezes equivocados, do senso comum, onde são partilhados saberes de um grupo. Os estereótipos "autorizam a interação verbal [...] eles aparecem à luz da ideologia* para certas correntes que exercitam a análise ideológica dos discursos - o estereótipo relaciona-se, assim, ao pré-construído, segundo Pêcheux" (AMOSSY, 1991, p. 215-216, asterisco da autora).

A generalização e atribuição de valor pré-construídas, na maioria das vezes negativas, discursivizam como estereótipos de um grupo. No caso da masculinidade, são lugares de poder a serem ocupados. Modelos de comportamento sexual, tanto masculino quanto feminino, podem se tornar prisões, fontes de sofrimento e angústia para o gênero

usada como ofensa para pessoas que se desviavam da norma cisgênera. A partir da década de 80 , começa a surgir a Teoria Queer, nas discussões sobre gênero.E o queer, então, começou a ser entendido como aquilo que é, por essência, "estranho", ou seja, fora dos padrões sociais.Não existe uma forma apenas de ser queer. Na verdade, o termo é usado para questionar ideias sobre gênero que são impostas pela sociedade. Termo ainda não consensual com o qual se denomina a pessoa que não se enquadra em nenhuma identidade ou expressão de gênero.Informações baseadas em Jesus (2012), entre outras leituras. 
que não se encaixa no real. Um real que designa "um corpus de regras operatórias transmitidas de uma geração a outra, cujo conteúdo ideológico se organizou" (PÊCHEUX, 2012, p. 33).

Na concepção da Análise de Discurso, todos os sujeitos são necessariamente atravessados pela ideologia e pelo inconsciente, independentemente do gênero. Ser sujeito é uma posição material linguístico-histórica produzida em meio ao jogo de contradições e tensões sócio ideológicas. É singular, pois é interpelado ideologicamente (ALTHUSSER, 1983) e não se trata do ser indivíduo, visto que é aquele que emerge entre a cadeia de significantes (LACAN, 1998) de modo único. Como afirma Henry (1992, p. 188-189): "b sujeito é sempre e ao mesmo tempo sujeito da ideologia e do inconsciente e isso tem a ver com o fato de nossos corpos serem atravessados pela linguagem antes de qualquer cogitação". Neste sentido, quais são os efeitos de sentido que a capa reproduzida abaixo (Figura 1) possibilita sobre a masculinidade?

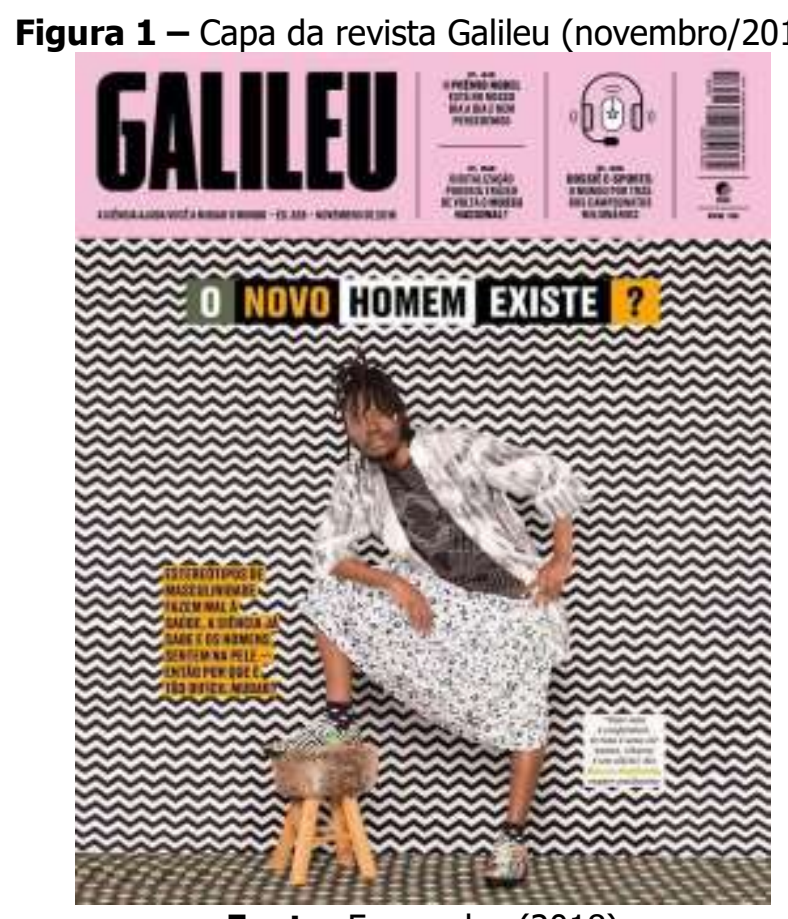

Fonte: Fernandes (2018)

Na capa de novembro de 2018, com registro do fotógrafo Dulla, a revista Galileu traz no centro da imagem o rapper brasileiro Rincon, homem negro, com barba e bigode, vestindo saia godê (com predominância da cor branca e detalhes pretos), camiseta preta com detalhes brancos e blazer de cor branca e detalhes em cinza. Ele está calçado com meias pretas de bolinhas brancas e tênis branco e preto com detalhes florais. Rincon está 
com uma das pernas apoiada sobre um banquinho de madeira, assim, o cotovelo direito apoia sobre essa perna enquanto que mão esquerda está apoiada na cintura. 0 rapper usa o cabelo endredado 3 amarrado no alto da cabeça, fazendo com que caiam sobre a testa como uma franja. Acima da cabeça, o enunciado "O novo homem existe?" Enquadrado, com as palavras em um revezamento de cores. $\mathrm{O}$ artigo " $\mathrm{O}$ ", em branco, está sobre um fundo verde. Já a palavra "homem" está em preto sobre um fundo branco, justamente o inverso de "existe", escrito em branco sobre um fundo preto. Por sua vez, a palavra "novo"está escrita em alaranjado sobre um fundo preto; o oposto do ponto de interrogação, escrito em preto sobre o fundo alaranjado. Todos os elementos da capa são uma sequência discursiva, uma vez que são possiveis de serem analisadas por meio do discurso, afinal não são somente as palavras da capa que configuram uma sequência discursiva: as cores, o tipo de letra, a diagramação, a postura na foto são todos um conjunto possibilidades discursivas.

O fundo da fotografia é preenchido pelas cores preta e branca, o que evidencia a faixa rosa na parte superior da revista, com o nome da publicação, preço, código de barras, editora, edição e chamadas para outras reportagens. Com isso, mesmo com as cores monocromáticas que parecem confundir a visão, a saia é o grande destaque da fotografia. A cor rosa, enquanto efeito do ideológico, pode estar relacionada relacionada ao feminino. Na parte inferior, próximo ao banco, com letras pretas sobre o fundo amarelo, está o enunciado sobre o qual nos deteremos com mais afinco.

Quadro 1: Manchete da capa da revista Galileu (novembro/2018) O novo homem existe? Estereótipos de masculinidade fazem mal à saúde. A ciência já sabe e os homens sentem na pele - então por que é tão difícil mudar?

\section{Fonte: Galileu (novembro/2018)}

"O novo homem existe?" A revista, ao nos indagar acerca da possibilidade de pensar em um homem diferente, permite também pensarmos em outros efeitos de sentido para o substantivo "homem", no singular. Estaria a revista concebendo o sentido de homem compreendido do ponto de vista filosófico, enquanto espécie humana? Ou a categoria homem no sentido sociológico, enquanto categoria "gênero"? O sentido dado a ler está

\footnotetext{
3 Termo usado para denominar o cabelo que está com dreadlocks, ou, dread (abreviatura) de palavra inglesa. Descreve um estilo de cabelo que são enrolados de forma cilíndrica ou trançados em mechas longas e finas. Também é utilizado como tratamento capilar, para crescimento do cabelo.( experiências próprias)
} 
relacionado à constituição sociológica que é atravessada pela categoria sexual masculina? Uma vez que, a palavra homem diz respeito à categoria gênero, e não está necessariamente ligado ao masculino, esta última está relacionada à categoria sexo biológico. Sendo assim, "homem" nunca é biológico, do ponto de vista sociológico. Nos estudos da filósofa Badinter (1993), a autora define que ser homem socialmente não existe uma definição, mas, significa tudo que não seja feminino.

Todos os adjetivos cujos sentidos estão atrelados ao ser feminino o homem rechaça, pois, em nome de uma masculinidade discursivizada como um real técnico racional, "o velho homem", os sujeitos masculinos devem ser fortes, corajosos, devem ter sensibilidade inibida, ser mais racionais, ter salários maiores que as mulheres, devem possuir um melhor poder econômico, ser homens (com H maiúsculo), ser mais inteligentes, devem ser viris, inclusive produzir filhos, e apenas "ajudar" a mulher nos afazeres domésticos.

Discursivamente, a indagação sobre a existência de um novo homem traz, para o fio do discurso, que há interdiscursivamente um "velho homem" ou uma roupagem de homem que vem sendo questionada não somente pelo movimento feminista, mas também pelos movimentos queer. O discurso sobre a possibilidade de um novo é sustentado pela estratificação de outras formulações já realizadas sobre o velho homem. É a partir do velho que é possível pensar na construção de sentidos desse novo homem na história. Há uma memória discursiva, como matrizes de efeitos congelados que estabilizam sentidos para o lugar que o homem deve ocupar, sobre "ser homem" - ser humano "cisheteropatriarcal".

A despeito das relações sociohistórica e cultural, o patriarcado pode ser entendido como um sistema político modelador de dominação masculina sob as mulheres, corroborado pelas instituições sociais, como por exemplo: a família nuclear, a igreja, entre outras . Onde o discurso sobre o gênero é binária. Ao nascer são atribuídas condições aos que biologicamente nascem macho somente para serem homens, e, à fêmea de serem mulheres. Sendo assim, "cis"ou cisgênero são pessoas que se identificam com o gênero que Ihe foi atribuído ao nascimento. Portanto, um ser humano cishetero é aquele em conformidade com seu gênero de nascimento tem orientação sexual, ou atração afetivossexual pelo gênero oposto. Essa memória discursiva está na matriz dos sentidos em relação ao ser homem. A revista, no enunciado "o novo homem existe?", questiona a possibilidade de existência de um novo homem, uma vez que há inscritos na história social, pré-construídos sobre o substantivo homem, isto é, "como se esse elemento já se 
encontrasse aí" (PÊCHEUX, 2009, p. 89). A adjetivação "o novo" causa o efeito de que existe há pouco tempo, que surgiu recentemente, em oposição ao velho: o homem "metrossexual" (fusão dos termos "metropolitano" e "heterossexual"). Entretanto, Badinter (1993, p. 165) denomina esse novo padrão de masculinidade de "homem reconciliado", o qual saberia encontrar um equilíbrio entre solidez e sensibilidade, capaz de reconciliar seus aspectos masculinos e femininos sem que nenhum desses aspectos seja apagado. São os espaços identitários de fronteira, ou entre-lugares identitários, evidenciados pelas teorias queer.

Para Nolasco (1995, p. 184) "o novo homem é produto de mais uma possibilidade concedida pelo individualismo, e o que vem acontecendo não é ainda um movimento social". Da mesma maneira, Badinter (1993, p. 187), afirma que a proposta de novo homem condiz com o fato de homens "não se reconhecem[rem] nem na virilidade caricatural do passado, nem no repúdio à masculinidade. Eles já são herdeiros de uma primeira geração de mutantes".

Na mesma arte em que é feito esse questionamento, a revista Galileu traz a imagem de um homem com saia e cabelo comprido, elementos ideologicamente marcados como femininos. Há a naturalização de que para ser homem o cabelo deve ser curto e jamais se deve usar saia ou vestido. Segundo Porchat "roupas, gestos, olhares, falas, define-se um conjunto de estilos corporais que [...] por imposição das normas de gênero [...] todo esse aparato só alcança uma falsa estabilização de gênero" (PORCHAT, 2014, p. 90). Ou seja, há sentidos do movimento queer para além das concepções binárias de identidade (homem/mulher; hetero/homo; masculino/feminino) e, portanto, uma subversão de sentidos e políticas identitárias ancoradas em compreensões binárias de corpo. Um sujeito social que fornece, no exterior, um atravessamento de fronteira e limite imposto ao corpo, uma não materialização da norma identitária sexual, revelando sentidos de exploração de ambiguidade e fluidez própria da teoria queer.

A revista indaga se há um novo homem e, logo em seguida, em resposta, afirma que há estereótipos de masculinidade, ou seja, interdiscursivamente são retomados sentidos de uma formação discursiva de masculinidade relacionada ao "velho homem" e, não, ao novo homem indagado. Assim, podemos afirmar que duas formações discursivas são possíveis nesse discurso: a formação discursiva do novo homem e a da masculinidade estereotipada do velho homem. Entretanto, para compor o discurso, a revista Galileu se vale da imagem 
de um homem negro, uma masculinidade subalternizada que é trazida para o discurso, de maneira que ressignifica os sentidos de masculinidade. Um negro para o novo homem enuncia um lugar político, provoca sentidos de protagonismo, efeitos de uma nova forma de existência da figura do negro, não hipersexualizado, tampouco estereotipado.

Os estereótipos de masculinidade configuram uma FD com aparência dissimulada pela transparência de sentidos já estabilizados e relacionados ao interdiscurso sobre o que deveria ou deve "ser homem". É uma constituição de dependência que fala o que socialmente está estabelecido sobre o masculino: ser cisheteropatriarcal. Há um conjunto de discursos independentemente acerca de atributos sociais adequados à homens, sejam eles individuais ou partilhados. Entretanto, a revista apresenta uma ressignificação dessa masculinidade pertencente ao todo complexo dominante (PÊCHEUX, 2009, p. 149). É preciso recuperar os saberes discursivizados sobre a FD do velho homem, o homem da masculinidade estereotipada: independentemente, o ser homem tradicional fala antes, sustentando o intradiscurso, para a possibilidade de movência de sentidos

Estereótipos, substantivo masculino no plural, é a singularização do substantivo feminino masculinidade, oposição de feminilidade. Discursivamente os estereótipos são muitos em contraposição à masculinidade, evocam sentidos pré-construídos sobre um tipo de masculinidade: De acordo com a visão estereotipada, o único modelo. o único modelo de masculinidade possível seria o da masculinidade hegemônica: branca, heterossexual, dominante - um ser humano universalmente generalizável, e, geralmente, de classe econômica média alta, "associada ao fato de possuir, tomar, penetrar, dominar e afirmar, se necessário pela força" (BADINTER, 1993, p. 99).

O conceito, derivado do latim masculinus, visa delimitar espaços que deveriam ser ocupados pelos homens. Por sua vez, a hegemonia trabalha "através da produção de exemplos de masculinidade (como as estrelas dos esportes profissionais), símbolos que têm autoridade" (CONNELL; MESSERSCHMIDT; FERNANDES, 2013, p. 263). Como lembra a cientista social australiana, o termo hegemonia foi usado por Antônio Gramsci (1891-1937) na tentativa de compreender as dinâmicas das mobilizações estruturais das relações de classe. Advém desse contexto o conceito de masculinidade hegemônica, em detrimento às masculinidades plurais subalternizadas. As demais possibilidades de masculinidades não são contempladas no intradiscurso. Subalternizadas, a etnia, a classe social e a identidade sexual não são consideradas na masculinidade hegemônica. Essa masculinidade - no 
singular - hegemônica ecoa sentidos de um modelo ideal de homem, o homem-padrão, atingível por praticamente nenhum homem ocidental. Ao mesmo tempo, os homens que mais se aproximam desse modelo-padrão exercem sobre os demais a própria masculinidade, os efeitos de sentido de poder, de controle, de privilégio sobre as outras masculinidades possíveis e subalternizadas. Em outros termos, a masculinidade hegemônica é uma roupagem, uma representação performática "construída diante de outros homens, para os outros homens e contra a feminilidade por uma espécie de medo do feminino, e construída, primeiramente, dentro de si mesmo" (BOURDIEU, 2010, p. 67).

A revista, enquanto porta-voz, está inscrita em uma FD de voz de autoridade midiática, dessa forma enuncia que a ciência já sabe que na masculinidade hegemônica há malefícios para o próprio homem e para a sociedade, esse velho homem reproduz hierarquias exageradas e essencializa a diferença entre macho e fêmea, ignorando as diferenças e caegorização de gêneros. Contudo, no Brasil, em 2008, foi criada uma política de Estado, a Política Nacional de Atenção Integral à Saúde do Homem - princípios e diretrizes - PNAISH (BRASIL, 2008), por meio do Sistema Único de Saúde (SUS), através da Secretaria de Atenção à Saúde e do Ministério da Saúde, considerando que o sexo socialmente masculinizado constitui problemas de saúde pública, já que os homens não vão regularmente ao médico e acabam morrendo mais cedo por falta de cuidados com a saúde pelo simples fato de não procurar a medicina. A política visa desde o fomento de recursos para pesquisa sobre a saúde dos homens, até o estimúlo entre eles para o cuidado com a própria saúde, com seus corpos e com aqueles com quem se relacionam. Os estereótipos de masculinidade fazem mal à saúde, pois evocam sentidos de que os homens devido a um tipo de masculinidade não precisam ir regularmente ao médico, assim, não é a masculinidade que faz mal à saúde, mas, sim, os estereótipos que a constituem.

Então por que é tão difícil mudar? Mais uma vez a revista convoca o leitor a pensar possibilidades de respostas. Se a violência que os homens sofrem geralmente é provocada pelos estereótipos que sustentam a sua masculinidade, ou seja, os estereótipos da masculinidade é que provocam malefícios sentidos na pele, "por que é tão difícil mudar"? O advérbio de intensidade "tão" reforça o sentido do adjetivo 'difícil' que incide sobre o verbo "mudar".Tomemos o verbo mudar, diferentes significações transitivas e intransitivas, produzindo uma circularidade de efeitos em mudar a masculinidade. Mudar no sentido de deslocar a masculinidade; mudar no sentido de realizar alterações grandes ou pequenas; 
mudar para substituir por outra coisa diferente; mudar para transformar, converter a masculinidade em algo não maléfico. Esse mudar em relação à masculinidade desliza em seus sentidos, justamente pelas incompletudes e lacunas da língua e da história. Além disso, as próprias masculinidades são plurais e contraditórias, podendo evocar e performar diferentes repertórios em diferentes enquadres.

Além disso, mudar é difícil, porque a sociedade, assim como os discursos, não é homogênea. Ambos são contraditórios, possuem equívocos que the são constitutivos. Pêcheux (2012) adverte sobre a dificuldade de mudança, fazendo uma comparação "Lewis Carroll conseguiu descrever o mundo de Alice no País das Maravilhas com seus sorrisos sem gatos e suas personagens que encolhem, mas nenhum lógico poderia fazer o mesmo no País da Política" (PÊCHEUX, 2012, p. 252).

Parafraseando as considerações dos estudos de Medrado e Lyra (2008, p. 825), investigar sobre masculinidades vai muito além de perceber os efeitos de sentido nos discursos, mas, sim, apontar elementos culturais, "discutir preconceitos e estereótipos e repensar a possibilidade de construir outras versões e sentidos". Ao mesmo tempo, pensar masculinidades dentro de uma formação discursiva que é heterogênea em relação a si mesma, consiste em pensar "onde residem esses famosos implícitos, que estão 'ausentes por sua presença" (PÊCHEUX, 2007, p. 52), falo aqui de todos os discursos feministas e de gênero que se fazem presentes nos discursos sobre masculinidade pela presença-ausência, "estão disponíveis na memória discursiva como em um fundo de gaveta" (PÊCHEUX, 2007, p. 52).

Mudar a masculinidade hegemônica demanda pensar em mudanças regionalizadas, em pontos específicos. Compreender que o masculino é plural já é um passo inicial; compreender que o gênero é um construto, é compreender que esse lugar masculino hierarquizado, privilegiado, dominante no social, já é uma luta constante dentro do movimento feminista, que tem como princípio social, político e filosófico, a igualdade de gêneros, além dos movimentos queer que corroboram com a desestabilização da categoria gênero. Mas que, enquanto sujeitos de/na linguagem não se deve desconsiderar essencialmente que essa é ideológica, não é transparente, é ambígua, para, assim, falar de mudança.

Segundo Pêcheux (2012), a sociedade apresenta uma necessidade de homogeneidade lógica que ignora o equívoco, a falta e as contradições das relações sociais, 
as filiações sociohistóricas de identificações dos sujeitos pragmáticos frente às inúmeras urgências do cotidiano. Seria muito ingênuo pensar em mudanças rápidas ou radicais, mesmo com as diversas transformações perceptíveis nas últimas décadas. Um caminho seria apostar nas contradições, nas incertezas, nas ambiguidades, nos movimentos.

A defesa de uma masculinidade hegemônica, praticamente inacessível, faz mal, é tóxica (SINAY, 2016), a ciência já sabe, já descobriu através de diversas pesquisas, e a revista enuncia que os homens sentem na pele esses estereótipos. A expressão "sentir na pele" não seria sentir na superfície, mas no íntimo que exala na pele, é vivenciar, experimentar as sensações que geralmente são ruins.Visto que, os homens sintam na pele os efeitos de sua agressividade excessiva, de seus medos físicos e psicológicos; sintam medo de serem fracos, vulneráveis e de se mostrarem obsessivos ao poder e ao dinheiro. Bell Hooks (1994) diz que quando as mulheres sentem dores emocionais, a sociedade possibilita e incentiva-as a falarem umas com as outras: as mulheres devem falar de suas emoções. Já em relação aos homens, a postura social machista, as normas patriarcais, os ensinam o historicismo racional, ou seja, que é mais homem aquele que não sente nada. Todos os sentimentos devem ser escondidos, camuflados e os homens devem esperar que o sentimento simplesmente desapareça. A única emoção que o patriarcado permite a eles é o sentimento de raiva, ficar bravo. O sentimento de raiva é, por consequência, a agressividade e a violência expressadas para mascarar a sua dor e as suas angústias, suas vítimas são as mulheres, outros homens ou eles mesmos.

\section{(In) concluindo: fios finais}

Para a revista Galileu, só um novo homem, do sexo masculino, não sofreria de males causados pela masculinidade. Segundo a publicação, os estereótipos fazem mal à saúde, não à masculinidade. Sendo assim, a masculinidade faz bem à saúde do homem, desde que seja pluralizada e ressignificada em outras bases, menos atreladas a concepções essencialistas e binárias de gênero. Contudo, há resistência à mudança, visto que, necessitaria admitir a emancipação feminina, a defasagem do modelo patriarcal e a desconstrução da hegemonia masculina, em detrimento do feminino e de outras masculinidades subalternizadas.

Discutir os efeitos de sentido sobre a masculinidade maléfica e seus estereótipos é mais do que necessário. Para compreender os estereótipos da masculinidade que fazem 
mal à saúde, é necessário resgatar sentidos por meio do interdiscurso e da memória discursiva, saberes já discursivizados. Ao mesmo tempo, pensar masculinidades dentro de uma formação discursiva que é heterogênea em relação a si mesma, consiste em pensar na presença dos implícitos não apresentados no intradiscurso, mas, interdiscursivamente apresentados em relação a todos os discursos feministas e de gênero que se fazem presentes nos discursos sobre masculinidade pela presença-ausência na memória discursiva. É preciso lembrar que não há uma teoria pronta para acessar e analisar o objeto, pois em Análise de Discurso há que se fazer o deslocamento de conceitos e entrecruzamentos da história (materialismo histórico), da linguística e da psicanálise.

No discurso da revista, homem é apresentado como sinônimo de masculinidade, apesar de homem não ser o mesmo que masculinidade; são diferentes: a masculinidade são os atributos, as práticas do ser masculino. Já o sentido de homem muitas vezes é tomado como universal, ou da categoria homem. Está na hora de iniciarmos uma desconstrução do homem universal e hegemônico. Essa concepção estruturada reverbera machismo, sentidos pratiarcais, por isso há que se pensar em masculinidades no plural. Porque os estereótipos fazem mal para o homem e para a sociedade, são generalizações que, como tal, necessariamente excluem, marginalizam, hierarquizam.

Mas o processo de desnaturalização se inicia quando mais discursos, como o veiculado pela revista Galileu forem replicados. Sim, há de se modificar os discursos. Mas a mudança é interesse de quem? Provavelmente seja do masculino que mais está longe, mais subalternizado em relação a masculinidade hegemônica. É preciso não cair nos discursos vitimistas, uma vez que a condição masculina na hierarquia social ainda se encontra em superioridade à feminina. Talvez por isso seja tão difícil mudar. Entretanto, a luta para acabar com os estereótipos ainda tem sido uma constante pelos movimentos de mulheres. A luta contra o patriarcado, o machismo e tantos outras práticas estereotipadas, são mais incisivas no feminino. No entanto, os homens precisam compreender sua masculinidade, para auxiliar nessa mudança que é feminista, uma perspectiva de igualdade e não superioridade feminina. Ou seja, é um processo de desconstrução, também do masculino em favor do feminino e do masculino também. Porque a hegemonia da masculinidade é como um submarino "está sempre lá, não necessariamente no fundo do mar, mas nas profundezas de um paradigma que estrutura o retorno do acontecimento sem profundidade" (PÊCHEUX, 2007, p. 55). A título de encerramento, é necessário dizer que 
os efeitos de sentido ainda são os mesmos, não existe um novo homem, embora haja uma crise em relação à masculinidade hegemônica, ainda não há esse novo homem, o que há são reflexões e microrresistências, que têm produzido fissuras na estrutura hegemônica.

\section{Referências}

ALTHUSSER, Louis. Aparelhos ideológicos do estado. Rio de Janeiro: Graal, 1983.

AMOSSY, Ruth. Estereótipo. In: CHARAUDEAU, Patrick; MAINGUENEAU, Dominique. Dicionário de análise do discurso. São Paulo: Contexto, 1991.

BADINTER, Elisabeth. XY: sobre a identidade masculina. Rio de Janeiro: Nova Fronteira, 1993.

BOURDIEU, Pierre. A dominação masculina. 9. ed. Tradução Maria Helena Kühner. Rio de Janeiro: Ed. Bertrand Brasil, 2010.

BRASIL. Ministério da Saúde. Fundação Oswaldo Cruz. Instituto Nacional de Saúde da Mulher da Criança e do Adolescente Fernandes Figueira. Fortalecimento da política nacional de atenção integral à saúde do homem (PNAISH): compromisso versus ação na atenção básica. Brasília: MEC, 2008.

BUTLER, Judith. Bodies that matter: on the discursive limits of "sex". New York, Routledge, 1993.

BUTLER, Judith. The psychic life of power: theories in subjection. California: Stanford University Press, 1997.

CONEIN, Bernard et al. Materialidades discursivas. Revisão técnica da tradução de Eni Orlandi e José Horta Nunes. Campinas: Editora da Unicamp, 2016.

CONNELL, Raewyn; MESSERSCHMIDT, James W.; FERNANDES, Felipe Bruno Martins. Masculinidade hegemônica: repensando o conceito. Estudos Feministas, Rio de Janeiro, p. v. 21, n. 1, p. 241-282, abr. 2013.

FERNANDES, Nathan. O rosa é uma cor bonita, usar saia é confortável e chorar é um alívio: o rapper Rincon Sapiência conta como desafia estereótipos e enfrenta críticas por usar saia em show. Galileu, São Paulo, 18 nov 2018. Disponível em:

https://revistagalileu.globo.com/Revista/noticia/2018/11/o-rosa-e-uma-cor-bonita-usarsaia-e-confortavel-e-chorar-e-um-alivio.html. Acesso em: 10 dez. 2020.

HENRY, Paul. A ferramenta imperfeita: língua, sujeito e discurso. Campinas: Ed. Unicamp, 1992.

HOOKS, Bell. The will to change: men, masculinity, and love. New York: Routledge, 1994.

JESUS, Jaqueline Gomes de. Orientações sobre identidade de gênero: conceitos e termos. Brasília, 2012. 
LACAN, Jacques. Subversão do sujeito e dialética do desejo (1960). In: LACAN, Jacques. Escritos. Rio de Janeiro: Jorge Zahar, 1998. p. 807-842.

MEDRADO, Benedito; LYRA, Jorge. Por uma matriz feminista de gênero para os estudos sobre homens e masculinidades. Estudos feministas, Rio de Janeiro, v. 16, n. 3, p. 809840, 2008.

NOLASCO, Sócrates. O mito da masculinidade. Rio de Janeiro: Rocco, 1995.

PÊCHEUX, Michel. Análise de discurso: Michel Pêcheux. Textos escolhidos por Eni Puccinelli Orlandi. Campinas: Pontes Editores, 2012.

PÊCHEUX, Michel. Delimitações, inversões e deslocamentos. Tradução José Horta Nunes. Cadernos de Estudos Linguisticos, Campinas, n. 19, p. 7-24, jul./dez. 1990.

PÊCHEUX, Michel. Papel da memória. In: ACHARD, Pierre et al. (org.). Papel da memória. Tradução e introdução de José Horta Nunes. 3. ed. Campinas, SP: Pontes Editores, 2007. p. 49-57.

PÊCHEUX, Michel. Semântica e Discurso: uma crítica à afirmação do óbvio. Tradução Eni Puccinelli Orlandi. 4. ed. Campinas: Ed. Unicamp, 2009.

PÊCHEUX, Michel; FUCHS, Catherine. A propósito da análise automática do discurso: atualização e perspectivas. In: GADET, Françoise; HAK, Tony. Por uma análise automática do discurso: uma introdução à obra de Michel Pêcheux. Campinas: Ed. UNICAMP, 1997. p. 163-252.

PORCHAT, Patrícia. Psicanálise e transexualismo: desconstruindo gêneros e patologias com Judith Butler. Curitiba: Juruá, 2014.

SCOTT, Joan. Gênero: uma categoria útil de análise histórica. Educação \& Realidade, Porto Alegre, v. 20, n. 2, p. 71-99, jul./dez. 1995.

SANTOS, Eliana Cristina Pereira. A imagem do professor nas capas da Revista Nova Escola: a circularidade do sentido. 2013. 148 f. Dissertação (Mestrado em Letras) Universidade Estadual do Oeste do Paraná, Cascavel, 2013.

SINAY, Sergio. La masculinidad tóxica. Buenos Aires: Ediciones B, 2016.

Submetido em: $17 \mathrm{dez} .2020$. Aceito em: 01 abr. 2021. 